\title{
A methodological toolbox for investigating attentional strategy
}

\author{
Andrew B. Leber \& Jessica L. Irons \\ The Ohio State University
}

\begin{abstract}
Strategy is a crucial determinant for how attention is controlled. In recent years, researchers have deployed a growing variety of manipulations and dependent measures in service of understanding strategy. This work has revealed a striking degree of diversity and suboptimality in the use of attention, and it prompts the realization that more research on strategy is needed in order to fully understand and explain how attention works. Here, we highlight several approaches to investigate strategy, in what can be considered a "methodological toolbox" for researchers. These methods can be customized and combined flexibly in what we hope will be a continued expansion of inquiry into this important domain.
\end{abstract}

Keywords: Attentional control; strategy; cognitive effort

Andrew B. Leber and Jessica L. Irons, Department of Psychology, The Ohio State University.

Support was provided by NSF BCS-1632296.

Correspondence concerning this article should be addressed to Andrew B. Leber, Department of Psychology, The Ohio State University, 1835 Neil Avenue, Columbus, OH, 43210. Email: leber.30@osu.edu. 


\subsection{Introduction}

"You can do anything you set your mind to," goes the old adage. Of course, we do not always aim toward the loftiest goals, sometimes preferring to "just take it easy, man" [1]. These contrasting approaches to life are captured by the principles of maximizing and satisficing, in which individuals implement optimal or goodenough-to-get-by decision strategies, respectively [2]. The use of strategies like these, among others, has been broadly studied in a variety of domains across psychology [3-5], yet not as extensively in the domain of attention, the target topic of this special issue.

Nevertheless, it is critical that we understand how attentional strategy exerts its influence on performance. In this pursuit, it is prudent to first define it. Borrowing from several definitions of cognitive strategy [6-8], we define attentional strategy as a mental plan, or policy, guiding how individuals prioritize and select sensory information. It can impact multiple stages of task performance, from choosing whether to perform a given attentional task (e.g., should I actively search for my car keys or rest my eyes and ask my friend to do it?), to choosing which features and locations to prioritize during the task (e.g., search for the red keychain vs. the metal key), to deciding when to terminate/update task performance (e.g., should I keep searching this room or begin searching another room?). A comprehensive understanding of strategy thus invites examination of not how it dictates a single choice but rather a complete decision tree, guiding steps from start to finish in task performance.

To begin to appreciate the impact strategy makes on task performance, consider a seminal contribution from Bacon and Egeth, 25 years ago [9]. They questioned a now classic finding in which people searching for shape oddball targets suffer response time (RT) interference costs by salient, color oddball distractors [10]. While one could presume this distraction to be unavoidable, Bacon and Egeth posited that people were able to ignore the color oddball but simply were unmotivated to do so. Perhaps participants were satisficing, being unwilling to invest additional cognitive effort required to ignore the color singleton, especially since the cumulative RT costs of distraction across a full experiment only amounted to mere seconds [11]. Bacon and Egeth modified their task to discourage such satisficing, predicting that shifts toward a maximizing strategy would reduce the observed RT distraction effects. Results indeed revealed the distraction effects disappeared. Some debate surrounding their work has ensued [12], but we can credit the study with the powerful message that we ignore strategy at our peril. Investigating it is vital for developing complete models of attention, particularly in the real world, when strategy use is least constrained (for reviews emphasizing the importance of studying attentional strategy, see $[13,14])$.

\subsection{Methods for Investigating Attentional Strategy}

Our aim in this paper is a practical one: to encourage greater study of attentional strategy. This prompts consideration of roadblocks preventing such work. The overwhelming majority of studies on attention rely on the dependent measures of response time (RT) and accuracy. These metrics serve as gold standard tools in investigating attentional abilities, and they have been classically used in investigating some strategy indicators, such as the speed-accuracy tradeoff $[15,16]$. However, any single metric inherently carries limitations. Bacon and Egeth (1994) had to infer strategy by computing the difference in RT between distractor present and distractor absent conditions (see also [17,18]). Similar approaches need to be taken with accuracy [19]. More broadly, efforts to quantify strategy from RT and accuracy metrics largely rely on the comparison of two or more conditions [20-24]. Unfortunately, while producing great insights, difference scores are indirect and bring on unwanted statistical noise, especially when employed in individual differences and correlational designs [25]. Moreover, when strategy is estimated by comparing different conditions, it is impossible to measure strategy on individual trials. The good news is that many methods exist for investigating strategy, some more widely used than others, and a number of these are not subject to the same limitations difference scores. Therefore, it is prudent to use a diversity of converging methods. 
Here, we offer a "toolbox" of methods to study attentional strategy. We have divided them into both manipulations and measurements. The former can be deployed to elicit the use of a variety of strategies, while the latter provides ways to assess which strategies are chosen. The narrative review is accompanied by a schematic overview indicating which stages of task completion the methods might influence and/or probe (Figure 1), as well as a table summarizing when to use these approaches, along with some considerations to keep in mind (Table 1). No pair of methods is mutually exclusive; indeed, a robust study of strategy might use many at once. This list is also not exhaustive, as there are surely additional methods available.

\subsubsection{Strategy manipulations.}

\subsubsection{Instruction}

Instructions are a fixture in attention experiments, primarily because researchers want to make sure participants understand what is expected of them. However, instructions can also be manipulated in a variety of ways to shed light on strategy use. Explicit cues, such as those used by Posner, serve as perhaps the most famous example [26], showing that participants can strategically adjust how they process information based on expectations [27].

Bacon and Egeth, in a separate study from the one reviewed above, used instructions to mislead participants about the ratios of features in a conjunction search task (e.g., search for the red horizontal bar among red vertical and green horizontal bars), to determine if expectations about task structure would influence search strategy, finding some influence of instructions on strategy use [28]. Manipulations like this can be used to establish that a single task can be approached with more than one strategy.

When multiple strategies are available, and participants use a suboptimal one by default, instructions can also be deployed to help determine why. Participants may not know what the optimal strategy is; alternatively, they might know but are unable or unwilling to use the optimal strategy. Proulx found in one experiment that participants failed to use the optimal feature to guide a conjunction search [29]. In a second experiment, he explained the optimal strategy to participants; yet, about half of the participants still used the suboptimal strategy. For these participants, lack of explicit knowledge of the best strategy did not seem to explain their choices (see also $[23,30])$.

One consideration to keep in mind is that, particularly in studies similar to Proulx's, instructional manipulations can sometimes be subject to carry-over effects. Once instructed, the optimal strategy cannot be unlearned. In these cases, between-group designs should be selected.

\subsubsection{Reward}

Reward has become a widely used tool in modern attention research. The bulk of such studies have focused on value-driven learning, in which a specific stimulus can become behaviorally salient after participants learn to associate it with an expected payoff (see [31,32] for recent reviews). Value-driven learning may be considered strategic in nature [33], although in some cases it is viewed to be automatically driven [31,34].

One way reward can be used to arguably more directly manipulate strategy is to implement performance contingencies, also referred to as reward prospect, in which participants are paid more for overall better performance [35-38]. That is, if participants are paid more for faster response times, then they should be motivated to seek strategies yielding faster target detection.

This manipulation should be paired with a reliable measure of strategy, to distinguish between generic performance improvements (e.g., faster responding) vs. qualitative changes in chosen strategy (e.g., choosing the more efficient method to find the target).

\subsubsection{Strategy measures}




\subsubsection{Demand selection}

Imagine you can buy your favorite snack at the convenience store steps away for $\$ 2.75$ or at the market at the top of a steep hill for $\$ 2.00$. Is the climb worth saving $\$ 0.75$ ? This choice can be referred to as a demand selection, in which one weighs the relative physical or cognitive effort of the options in making their decision $[4,39]$. Pauszek and Gibson recently used this measure in an attention task [40]. After previously demonstrating that individuals often neglect to use valid spatial cues to facilitate visual target identification $[21,22,41]$, they questioned the extent to which individuals would consciously choose valid cue information that could both speed performance but incur greater effort to process. They had participants choose between a search task with no spatial cue vs. one that had a $70 \%$ valid spatial cue. Results showed a preference for the nocue task, revealing a strategic choice to forego information that could facilitate performance.

Demand selection, along with target choice and saccadic choice described below, is useful because it can measure strategy on each individual trial. One consideration to keep in mind is the potential for asymmetric practice effects, in which choosing one task more frequently produces learning improvements, thus making that task subjectively easier and more desirable.

\subsubsection{Target choice}

Demand selection features an explicit choice that is made prospectively. One might compare it to a New Year's resolution, in which someone announces their commitment before they are required to execute it. An individual might exhibit different behavior when strategy choices are made on the fly, during effortful task performance. We introduced a task called the adaptive choice visual search [42-44], in which participants view a large-scale display containing about a dozen items in one color (small subset) and about two-dozen in another color (large subset). One target is included in each subset, and participants can choose to report either target. The optimal strategy is to identify the smaller subset, configure an attentional template for that subset color (i.e., enter a state of control that prioritizes the chosen feature for selection), and then search within that subset for the associated target. Such a strategy yields substantially faster RTs than searching for the target in the larger subset or searching randomly. Critically, the size of each color subset changes dynamically over time, such that participants wishing to perform optimally must complete the effortful steps of waiting for the trial stimuli to appear, appraise the color information, determine which is the smaller subset, and occasionally update their search template to find the optimal target. Only some participants demonstrate optimal behavior in this task, and broad, stable individual differences have been observed [43].

\subsubsection{Saccadic choice}

Because stimulus perceptibility varies dramatically with eccentricity, where someone chooses to fixate their eyes greatly determines how profitably they can harvest information from the visual scene. Thus, the choice of saccade destinations represents a critical strategy component in attentional control [45-47].

Morvan and Maloney provided an elegant demonstration of this point [48]. They displayed three horizontally aligned boxes and presented a small target inside either the leftmost or rightmost box. Participants, who began the trial by fixating above or below the array, were allowed to saccade to one of the boxes. By measuring each participant's retinal sensitivity and then varying the spacing between the boxes, the researchers could predict an optimal saccade strategy. That is, if the boxes were spaced closely enough that a saccade to the center would allow accurate target discrimination in both adjacent boxes, the participant should fixate the center. If not, a center strategy would fail to acquire either target and lead to $0 \%$ accuracy, so the participant should choose either the left or right box for a $50 \%$ chance at successful identification. Results showed generally nonoptimal saccade choices, providing important insights into the strategic use of overt attention.

More recently, Nowakowska, Clarke, and Hunt presented an oriented bar target on either the left or right side of a large-scale display [49]. One side was filled with heterogeneously oriented distractors while the other was filled with homogeneously oriented distractors that were distinct from the target. This caused targets in the 
heterogeneous side to demand a serial search, while those on the homogeneous side popped out. For the latter, peripheral detection was possible, rendering a saccade to that side inefficient. Nevertheless, saccadic choice results revealed a striking tendency of observers to direct their first saccade on each trial to the homogeneous side, resulting in suboptimal performance.

\subsubsection{RT and accuracy differences}

As highlighted in the introduction, comparisons of RT and/or accuracy across multiple conditions have been a mainstay of attention research, such as comparing valid vs. invalid cues [21,26], the presence or absence of distractors $[9,10,20]$, or across different display set sizes [28].

Rajsic and colleagues analyzed relative display set sizes to reveal a "confirmation bias" in visual search [23,24]. In displays comprised of items in two color subsets, in which a target (e.g., "p") was always present in one of these colors, participants had to test a rule on each trial: e.g., does the "p" appear in blue? The optimal strategy is to search through the smaller subset and then infer the color of the target (if the " $p$ " is absent in the smaller red subset, then it must be in the larger blue subset). However, comparing RT across different color ratios revealed that participants largely searched within the subset matching the color named in the instruction. That is, participants attempted to directly confirm the rule (e.g., find a blue "p"), regardless if it was the fastest way to solve the search task (i.e., through inference).

\subsubsection{Speed-accuracy tradeoff}

As highlighted above, the speed-accuracy tradeoff is a longstanding method for probing attentional strategy $[15,16]$. It has classically been shown that participants can be incentivized with reward to prioritize either speed or accuracy [50]. More recently, Manohar and colleages showed that reward prospect does not just move someone along a speed vs. accuracy tradeoff curve but also enhances their overall performance [38].

Continuous performance tasks can expose tradeoffs in which prolonged performance leads to faster and more error-prone responding. Fortenbaugh and colleagues recently analyzed a massive sample of 10,000 participants, finding that this tradeoff function varies considerably with age, with a gradual shift toward prioritizing accuracy with advancing age [51]. This contrasted with their measures of ability, which showed peak performance in the early 40s, followed by a gradual decline.

There exist several ways to quantify the speed-accuracy tradeoff. One such approach, as implemented in sequential sampling models [52], derives from the logic that evidence toward choice thresholds, or boundaries, accumulates over time. Here, variation in speed-accuracy tradeoff is determined by how far alternative decision boundaries are separated from each other; greater separations represent a higher evidence threshold, which result in slower RTs and higher accuracy. In models like this, a robust analysis of strategy can be carried out on parameters relating to boundary separation. Recent work along these lines has suggested that boundary separation can be adjusted strategically over time [53,54]. This was recently exemplified by Palestro et al. [55], who had participants attend a field of moving dots and judge whether its global coherence was moving left vs. right. Here, an individual might initially aim for a high level of accuracy; but after a few moments, they might realize the task difficulty exceeds their ability such that continued time on the task would produce diminishing returns. Thus, it would make sense to "collapse" the separation between boundaries to reach a quick, albeit inaccurate, response [54]. Palestro et al.'s model results supported collapsing boundaries. Note that the optimal boundary separation by time function need not always collapse; it could remain constant or even diverge, depending on the specific task conditions [56]. Overall, analysis of boundary separation provides support that individuals strategically and dynamically adapt their speed-accuracy tradeoff over time.

\subsubsection{Response criterion}


Response criterion, or bias, is a classic metric of signal detection theory that is typically associated with strategy [57] (but see [58] for evidence that criterion can reflect perceptual biases in addition to strategy). Response criterion manifests when a decision is made about the information that has been gathered. Was the target present or absent? Where or what was it? Such decisional processes are an important component of many attention-related tasks and can be integrated into a task completion process, such as deciding whether to continue or quit a visual search [59].

Wolfe and Van Wert manipulated the rate of target prevalence across trials, and found that participants dynamically adjusted their response criteria to track prevalence (e.g., biasing toward target present responses when target prevalence is high) [60]. Suboptimal decision criteria have been revealed in other contexts, such as deciding which of two locations contains a target [61].

\subsubsection{Patch leaving}

This metric relates to both speed-accuracy tradeoff and signal detection theory, but as applied to the more complex domain of foraging, in which individuals search for an undefined number of targets (e.g., finding and collecting quarters for laundry). This contrasts with many visual search tasks that are satisfied upon finding one target (the car keys or any hair clip). In the foraging scenario, deciding when to stop searching a particular scene is a critical strategy component. Foraging behavior has classically been explained by Charnov's marginal value theorem, which holds that an organism will quit searching one local "patch" for food when it determines that the expected yield of switching to a new patch - while accounting for the cost of travel - will exceed that of the present patch [62]. This theorem has recently been applied to foraging behavior in visual search [63-65]. Cain et al. had participants search for a variable number of targets in each display and measured when people switched to the next display (i.e., patch leaving), as a function of how long it had been since the last target was found and of how many total targets had been collected [64]. The researchers were interested in how individuals updated their expectations, or Bayesian priors, based on target prevalence, which they manipulated between $25-75 \%$. Results showed reasonably optimal updating of patch leaving time based on prevalence, albeit with participants underestimating how variable a given display could be.

Fougnie et al. adjusted target prevalence rate in cyclical fashion over the course of trial blocks, to measure individuals' sensitivity to recent prevalence vs. global temporal structure of prevalence (i.e., "seasons") [66]. They found slower patch leaving during periods in which prevalence was on the rise compared to when it was falling, confirming sensitivity to global structure.

\subsubsection{Metacognitive report}

How much explicit knowledge do people have regarding their strategy use, and does this knowledge predict chosen strategy? Asking participants about their strategies can address these questions.

Kawahara presented a visual search task with no instructions; rather, he used an operant conditioning procedure to shape search performance to gain insight into people's 'default' strategy without any contamination of demand characteristics [67]. In particular, he wished to see if people naturally avoided salient singleton distractors. Overwhelmingly, they did not. After task performance, he asked participants to report the strategy they used, and the vast majority reported the strategy consistent with avoiding distraction; this revealed a striking lack of metacognition with respect to attentional strategy (see also [29]).

Some researchers have found impressively high metacognition. In our adaptive choice visual search, described above, we found correlations as high as $r=0.77$ between the self-reported rates of optimal strategy use and actual optimal strategy use [43]. 


\subsubsection{Subjective effort ratings}

Much of the work we have described here identifies the avoidance of cognitive effort as a key motivating factor in the choice of suboptimal strategies. To better understand the relationship between effort and strategy, effort costs must be quantified. Subjective ratings are a valuable place to begin $[68,69]$.

We used a manipulation to require our participants to use an optimal visual search strategy and subsequently collected subjective effort ratings; then participants all performed our adaptive choice task in which they were free to use an optimal or suboptimal strategy [43]. We found that people who reported the required-optimal task to be more effortful were less likely to choose the optimal strategy when given the option. These results show that subjective ratings can help characterize the relationship between effort and strategy use.

Subjective rating scales carry some potential limitations; participants may vary in how they match the rating scale to their subjective state, and their reports after task completion may not accurately reflect the subjective effort they experienced during performance.

\subsection{Conclusions}

We started by acknowledging that there is no single way to live our lives, and we focused this notion within the domain of attention: there is no single way to make use of our attentional abilities. Given the wide variation in strategy that people use in the lab - which is likely even more variable in the real world - it is incumbent upon attention researchers to carry out systematic, thorough investigations of attentional strategy, particularly if we wish to form a complete understanding of how attention works. We used this brief review format to offer a methodological toolbox to manipulate and measure strategy, which we view as a starting point rather than an exhaustive list. We hope that this work prompts researchers to consider new and productive ways to better understand the strategic use of attention control. 


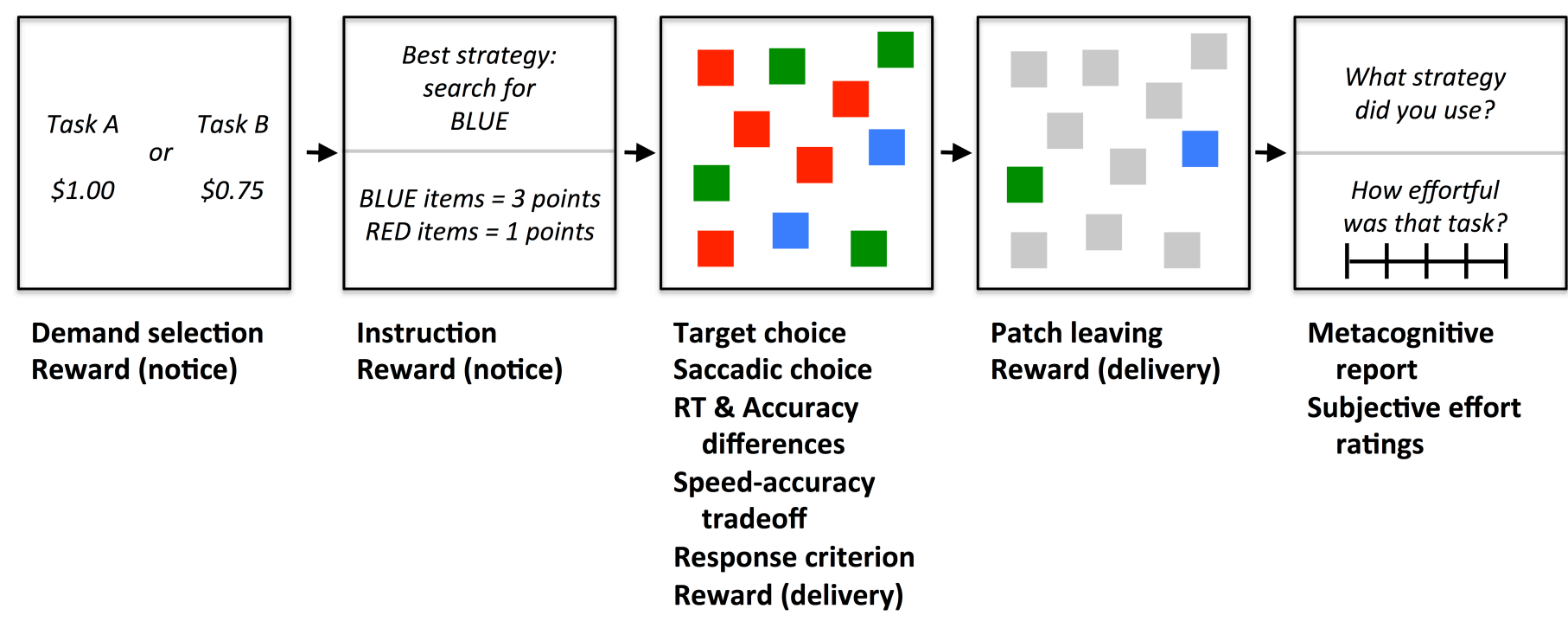

Figure 1. Schematic overview of the strategy manipulations and measures reviewed here, labeled at various points in time during a generic attention task. Descriptions of each are provided in Table 1 and in the text. Reward can be used at multiple stages; notice of reward structure can be provided at the start of the task, and performance-contingent delivery of reward can be provided upon response. Note that not all metrics are applicable to all tasks; for instance, tasks with a target choice are generally incompatible with foraging tasks that contain many potential targets. 


\section{Annotated References}

** [4] A. Shenhav, S. Musslick, F. Lieder, W. Kool, T.L. Griffiths, J.D. Cohen, M.M. Botvinick, Toward a Rational and Mechanistic Account of Mental Effort, Annu. Rev. Neurosci. 40 (2017) 99-124. doi:10.1146/annurev-neuro-072116-031526.

A comprehensive review of the relationship between mental effort and control strategy, focusing on mechanisms that underlie these related constructs.

** [43] J.L. Irons, A.B. Leber, Characterizing individual variation in the strategic use of attentional control., J. Exp. Psychol. Hum. Percept. Perform. 44 (2018) 1637-1654. doi:10.1037/xhp0000560.

Implementation of the Adaptive Choice Visual Search that combines metrics of target choice, metacognitive report, and subjective effort ratings, to both reveal a wide range of variability across individuals and link this variability to cognitive effort.

* [49] A. Nowakowska, A.D.F. Clarke, A.R. Hunt, Human visual search behaviour is far from ideal, Proc. R. Soc. B Biol. Sci. 284 (2017) 20162767. doi:10.1098/rspb.2016.2767

Uses a saccadic choice measure to reveal surprisingly suboptimal visual search strategies.

* [56] G. Malhotra, D.S. Leslie, C.J.H. Ludwig, R. Bogacz, Time-varying decision boundaries: insights from optimality analysis, Psychon. Bull. Rev. 25 (2018) 971-996. doi:10.3758/s13423-017-1340-6.

A theoretical overview of speed-accuracy tradeoff and decision boundaries, making the case that optimal boundary separation varies over time depending on task context.

* [65] K.A. Ehinger, J.M. Wolfe, When is it time to move to the next map? Optimal foraging in guided visual search, Atten. Percept. Psychophys. 78 (2016) 2135-2151. doi:10.3758/s13414-016-1128-1.

A complex visual foraging study, using satellite image data as stimuli. Provides an expanded discussion of patch leaving and tests a Bayesian model related to Charnov's marginal value theorem.

\section{References}

[1] J. Coen, E. Coen, The Big Lebowski, Polygram Filmed Entertainment, 1998.

[2] H.A. Simon, Rational choice and the structure of the environment., Psychological Review. 63 (1956) 129138. doi:10.1037/h0042769.

[3] L.M. Reder, C.D. Schunn, Strategy Worlds: Predicting Adaptivity in a Dynamic Task, Attention and Performance XVII. (1999) 315-342.

[4] A. Shenhav, S. Musslick, F. Lieder, W. Kool, T.L. Griffiths, J.D. Cohen, M.M. Botvinick, Toward a Rational and Mechanistic Account of Mental Effort, Annual Review of Neuroscience. 40 (2017) 99-124. doi:10.1146/annurev-neuro-072116-031526. 
[5] B. Schwartz, A. Ward, J. Monterosso, S. Lyubomirsky, K. White, D. R. Lehman, Maximizing versus satisficing: Happiness is a matter of choice., Journal of Personality and Social Psychology. 83 (2002) 11781197. doi:10.1037//0022-3514.83.5.1178.

[6] M.W. Conley, Cognitive strategy instruction for adolescents: What we know about the promise, what we don't know about the potential, Harvard Educational Review. 78 (2008) 84-106. doi:10.17763/haer.78.1.j612282134673638.

[7] C.A. Sangster, C. Beninger, H.J. Polatajko, A. Mandich, Cognitive Strategy Generation in Children with Developmental Coordination Disorder, Canadian Journal of Occupational Therapy. 72 (2005) 67-77. doi:10.1177/000841740507200201.

[8] J.A. Dole, J.D. Nokes, D. Drits, J.D. Nokes, D. Drits, Cognitive Strategy Instruction, Handbook of Research on Reading Comprehension. (2014). doi:10.4324/9781315759609-29.

[9] W.F. Bacon, H.E. Egeth, Overriding stimulus-driven attentional capture, Perception \& Psychophysics. 55 (1994) 485-496. doi:10.3758/BF03205306.

[10] J. Theeuwes, Perceptual selectivity for color and form, Perception \& Psychophysics. 51 (1992) 599-606. doi:10.3758/BF03211656.

[11] H.E. Egeth, C.J. Leonard, A.B. Leber, Why salience is not enough: Reflections on top-down selection in vision, Acta Psychologica. 135 (2010) 130-132. doi:10.1016/j.actpsy.2010.05.012.

[12] J. Theeuwes, Top-down and bottom-up control of visual selection, Acta Psychologica. 135 (2010) 77-99. doi:10.1016/j.actpsy.2010.02.006.

[13] A.D.F. Clarke, A. Nowakowska, A.R. Hunt, Seeing beyond salience and guidance: the role of bias and decision in visual search, PsyArXiv. (2019, July 1). doi:10.31234/osf.io/h8azb.

[14] J. Irons, A.B. Leber, Developing an individual profile of attentional control strategy, PsyArXiv. (2019, August 20). doi:10.31234/osf.io/5a4hx.

[15] P.M. Fitts, Cognitive aspects of information processing: III. Set for speed versus accuracy, Journal of Experimental Psychology. 71 (1966) 849-857. doi:10.1037/h0023232.

[16] R.P. Heitz, The speed-accuracy tradeoff: history, physiology, methodology, and behavior, Frontiers in Neuroscience. 8 (2014). doi:10.3389/fnins.2014.00150.

[17] J.D. Cosman, S.P. Vecera, Context-dependent control over attentional capture., Journal of Experimental Psychology: Human Perception and Performance. 39 (2013) 836-848. doi:10.1037/a0030027.

[18] A.B. Leber, H.E. Egeth, It's under control: Top-down search strategies can override attentional capture, Psychonomic Bulletin \& Review. 13 (2006) 132-138. doi:10.3758/BF03193824.

[19] C.L. Folk, A.B. Leber, H.E. Egeth, Made you blink! Contingent attentional capture produces a spatial blink, Perception \& Psychophysics. 64 (2002) 741-753. doi:10.3758/BF03194741.

[20] A.B. Leber, J.-I. Kawahara, Y. Gabari, Long-term abstract learning of attentional set., Journal of Experimental Psychology: Human Perception and Performance. 35 (2009) 1385-1397. doi:10.1037/a0016470.

[21] J.R. Pauszek, B.S. Gibson, The Least Costs Hypothesis: A rational analysis approach to the voluntary symbolic control of attention., Journal of Experimental Psychology: Human Perception and Performance. 44 (2018) 1199-1215. doi:10.1037/xhp0000527.

[22] J.R. Pauszek, B.S. Gibson, High spatial validity is not sufficient to elicit voluntary shifts of attention, Attention, Perception, \& Psychophysics. 78 (2016) 2110-2123. doi:10.3758/s13414-016-1097-4.

[23] J. Rajsic, J.E.T. Taylor, J. Pratt, Out of sight, out of mind: Matching bias underlies confirmatory visual search, Attention, Perception, \& Psychophysics. 79 (2017) 498-507. doi:10.3758/s13414-016-1259-4.

[24] J. Rajsic, D.E. Wilson, J. Pratt, Confirmation bias in visual search., Journal of Experimental Psychology: Human Perception and Performance. 41 (2015) 1353-1364. doi:10.1037/xhp0000090. 
[25] G. Johns, Difference score measures of organizational behavior variables: A critique, Organizational Behavior and Human Performance. 27 (1981) 443-463. doi:10.1016/0030-5073(81)90033-7.

[26] M.I. Posner, Y. Cohen, Components of Visual Orienting, in: H. Bouma, D.G. Bouwhuis (Eds.), Attention and Performance X: Control of Language Processes, Lawrence Erlbaum, London, 1984: pp. 531-556.

[27] E. Awh, M. Matsukura, J.T. Serences, Top-down control over biased competition during covert spatial orienting., Journal of Experimental Psychology. Human Perception and Performance. 29 (2003) 52-63. doi:10.1037/0096-1523.29.1.52.

[28] W.F. Bacon, H.E. Egeth, Goal-directed guidance of attention: Evidence from conjunctive visual search, Journal of Experimental Psychology: Human Perception and Performance. 23 (1997) 948-961. doi:10.1037/0096-1523.23.4.948.

[29] M.J. Proulx, Individual Differences and Metacognitive Knowledge of Visual Search Strategy, PLoS ONE. 6 (2011) e27043. doi:10.1371/journal.pone.0027043.

[30] J. Irons, A. Leber, Ignorance vs. laziness: Why do people use suboptimal attentional control strategies?, Journal of Vision. 18 (2018) 630-630. doi:10.1167/18.10.630.

[31] B.A. Anderson, The attention habit: how reward learning shapes attentional selection, Annals of the New York Academy of Sciences. 1369 (2016) 24-39. doi:10.1111/nyas.12957.

[32] A. Bourgeois, L. Chelazzi, P. Vuilleumier, How motivation and reward learning modulate selective attention, in: Progress in Brain Research, Elsevier, 2016: pp. 325-342. https://linkinghub.elsevier.com/retrieve/pii/S0079612316300644 (accessed July 24, 2019).

[33] S. Shomstein, J. Johnson, Shaping Attention With Reward: Effects of Reward on Space- and Object-Based Selection, Psychological Science. 24 (2013) 2369-2378. doi:10.1177/0956797613490743.

[34] J. Theeuwes, Goal-driven, stimulus-driven, and history-driven selection, Current Opinion in Psychology. 29 (2019) 97-101. doi:10.1016/j.copsyc.2018.12.024.

[35] B. van den Berg, R.M. Krebs, M.M. Lorist, M.G. Woldorff, Utilization of reward-prospect enhances preparatory attention and reduces stimulus conflict, Cognitive, Affective, \& Behavioral Neuroscience. 14 (2014) 561-577. doi:10.3758/s13415-014-0281-z.

[36] L. Pessoa, J.B. Engelmann, Embedding reward signals into perception and cognition, Frontiers in Neuroscience. 4 (2010). doi:10.3389/fnins.2010.00017.

[37] L. Chelazzi, A. Perlato, E. Santandrea, C. Della Libera, Rewards teach visual selective attention, Vision Research. 85 (2013) 58-72. doi:10.1016/j.visres.2012.12.005.

[38] S.G. Manohar, T.T.-J. Chong, M.A.J. Apps, A. Batla, M. Stamelou, P.R. Jarman, K.P. Bhatia, M. Husain, Reward Pays the Cost of Noise Reduction in Motor and Cognitive Control, Current Biology. 25 (2015) 1707-1716. doi:10.1016/j.cub.2015.05.038.

[39] W. Kool, J.T. McGuire, Z.B. Rosen, M.M. Botvinick, Decision making and the avoidance of cognitive demand., Journal of Experimental Psychology: General. 139 (2010) 665-682. doi:10.1037/a0020198.

[40] J.R. Pauszek, B.S. Gibson, The role of cognitive effort minimization in voluntary attentional control., in: New Orleans, LA, 2018.

[41] J.R. Pauszek, B.S. Gibson, Dealing with distractors in the spatial cueing paradigm can reflect the strategic influence of cognitive effort minimization rather than a limit to selective attention, Visual Cognition. (2019) 1-17. doi:10.1080/13506285.2019.1590488.

[42] H.A. Hansen, J.L. Irons, A.B. Leber, Taking stock: The role of environmental appraisal in the strategic use of attentional control, Attention, Perception, \& Psychophysics. (2019). doi:10.3758/s13414-019-01769-6.

[43] J.L. Irons, A.B. Leber, Characterizing individual variation in the strategic use of attentional control., Journal of Experimental Psychology: Human Perception and Performance. 44 (2018) 1637-1654. doi:10.1037/xhp0000560. 
[44] J.L. Irons, A.B. Leber, Choosing attentional control settings in a dynamically changing environment, Attention, Perception, \& Psychophysics. 78 (2016) 2031-2048. doi:10.3758/s13414-016-1125-4.

[45] W.R. Boot, A.F. Kramer, E. Becic, D.A. Wiegmann, T. Kubose, Detecting Transient Changes in Dynamic Displays: The More You Look, the Less You See, Human Factors. (2006) 15.

[46] C. Araujo, E. Kowler, M. Pavel, Eye movements during visual search: the costs of choosing the optimal path, Vision Research. 41 (2001) 3613-3625. doi:10.1016/S0042-6989(01)00196-1.

[47] C.C. Williams, A. Pollatsek, K.R. Cave, M.J. Stroud, More than just finding color: Strategy in global visual search is shaped by learned target probabilities, Journal of Experimental Psychology: Human Perception and Performance. 35 (2009) 688-699. doi:10.1037/a0013900.

[48] C. Morvan, L.T. Maloney, Human Visual Search Does Not Maximize the Post-Saccadic Probability of Identifying Targets, in: PLoS Computational Biology, 2012. doi:10.1371/journal.pcbi.1002342.

[49] A. Nowakowska, A.D.F. Clarke, A.R. Hunt, Human visual search behaviour is far from ideal, Proceedings of the Royal Society B: Biological Sciences. 284 (2017) 20162767. doi:10.1098/rspb.2016.2767.

[50] W.A. Wickelgren, Speed-accuracy tradeoff and information processing dynamics, Acta Psychologica. 41 (1977) 67-85. doi:10.1016/0001-6918(77)90012-9.

[51] F.C. Fortenbaugh, J. DeGutis, L. Germine, J.B. Wilmer, M. Grosso, K. Russo, M. Esterman, Sustained Attention Across the Life Span in a Sample of 10,000: Dissociating Ability and Strategy, Psychological Science. 26 (2015) 1497-1510. doi:10.1177/0956797615594896.

[52] R. Ratcliff, A theory of memory retrieval, Psychol. Rev. 85 (1978) 59-108.

[53] J. Ditterich, Evidence for time-variant decision making, European Journal of Neuroscience. 24 (2006) 3628-3641. doi:10.1111/j.1460-9568.2006.05221.x.

[54] M.N. Shadlen, R. Kiani, Decision Making as a Window on Cognition, Neuron. 80 (2013) 791-806. doi:10.1016/j.neuron.2013.10.047.

[55] J.J. Palestro, E. Weichart, P.B. Sederberg, B.M. Turner, Some task demands induce collapsing bounds: Evidence from a behavioral analysis, Psychonomic Bulletin \& Review. 25 (2018) 1225-1248. doi:10.3758/s13423-018-1479-9.

[56] G. Malhotra, D.S. Leslie, C.J.H. Ludwig, R. Bogacz, Time-varying decision boundaries: insights from optimality analysis, Psychonomic Bulletin \& Review. 25 (2018) 971-996. doi:10.3758/s13423-017-1340-6.

[57] D.M. Green, J.A. Swets, Signal detection theory and psychophysics, John Wiley, Oxford, England, 1966.

[58] J.K. Witt, J.E.T. Taylor, M. Sugovic, J.T. Wixted, Signal Detection Measures Cannot Distinguish Perceptual Biases from Response Biases, Perception. 44 (2015) 289-300. doi:10.1068/p7908.

[59] M.M. Chun, Jeremy, M. Wolfe, Just say no: How are visual searches terminated when there is no target present? Cognitive Psychology, 30, 39-78.spatial-frequency uncertainty, Vision Research. (1996) 401408.

[60] J.M. Wolfe, M.J. Van Wert, Varying Target Prevalence Reveals Two Dissociable Decision Criteria in Visual Search, Current Biology. 20 (2010) 121-124. doi:10.1016/j.cub.2009.11.066.

[61] J.F. Ackermann, M.S. Landy, Suboptimal decision criteria are predicted by subjectively weighted probabilities and rewards, Attention, Perception, \& Psychophysics. 77 (2015) 638-658. doi:10.3758/s13414-014-0779-z.

[62] E.L. Charnov, Optimal foraging, the marginal value theorem, Theoretical Population Biology. 9 (1976) 129-136. doi:10.1016/0040-5809(76)90040-X.

[63] J.M.C. Hutchinson, A. Wilke, P.M. Todd, Patch leaving in humans: can a generalist adapt its rules to dispersal of items across patches?, Animal Behaviour. 75 (2008) 1331-1349. doi:10.1016/j.anbehav.2007.09.006. 
[64] M.S. Cain, E. Vul, K. Clark, S.R. Mitroff, A Bayesian Optimal Foraging Model of Human Visual Search, Psychological Science. 23 (2012) 1047-1054. doi:10.1177/0956797612440460.

[65] K.A. Ehinger, J.M. Wolfe, When is it time to move to the next map? Optimal foraging in guided visual search, Attention, Perception, \& Psychophysics. 78 (2016) 2135-2151. doi:10.3758/s13414-016-1128-1.

[66] D. Fougnie, S.M. Cormiea, J. Zhang, G.A. Alvarez, J.M. Wolfe, Winter is coming: How humans forage in a temporally structured environment., Journal of Vision. 15 (2014) 1. doi:10.1167/15.11.1.

[67] J. Kawahara, Identifying a "default" visual search mode with operant conditioning, Acta Psychologica. 135 (2010) 38-49. doi:10.1016/j.actpsy.2010.05.002.

[68] S.G. Hart, L.E. Staveland, Development of NASA-TLX (Task Load Index): Results of Empirical and Theoretical Research, in: P.A. Hancock, N. Meshkati (Eds.), Advances in Psychology, North-Holland, 1988: pp. 139-183. doi:10.1016/S0166-4115(08)62386-9.

[69] T.L. Dunn, E.F. Risko, Toward a Metacognitive Account of Cognitive Offloading, Cognitive Science. 40 (2016) 1080-1127. doi:10.1111/cogs.12273. 
Table 1. Manipulations and measures of attentional strategy.

\begin{tabular}{|c|c|c|c|c|}
\hline \multicolumn{5}{|l|}{ Manipulations } \\
\hline Name & $\begin{array}{l}\text { Processing stage } \\
\text { targeted }\end{array}$ & Description & When to use & Considerations \\
\hline Instruction & $\begin{array}{l}\text { Depends on } \\
\text { strategy component } \\
\text { of interest }\end{array}$ & $\begin{array}{l}\text { Manipulated across groups or } \\
\text { conditions to elicit divergent strategies }\end{array}$ & $\begin{array}{l}\text { To verify whether divergent strategies can } \\
\text { impact task performance; examine role of } \\
\text { explicit task knowledge }\end{array}$ & $\begin{array}{l}\text { Cannot always ensure compliance; susceptible to carry- } \\
\text { over effects in within-subject design }\end{array}$ \\
\hline Reward & $\begin{array}{l}\text { Depends on } \\
\text { strategy component } \\
\text { of interest }\end{array}$ & $\begin{array}{l}\text { Performance-contingent reward (i.e., } \\
\text { reward prospect) used to incentivize } \\
\text { optimal strategy }\end{array}$ & $\begin{array}{l}\text { To verify whether divergent strategies can } \\
\text { impact task performance; used when strategy } \\
\text { might be linked to effort or motivation }\end{array}$ & $\begin{array}{l}\text { Generic improvements (i.e., overall speeding) should be } \\
\text { distinguished from qualitative changes in strategy (i.e., } \\
\text { choose the more efficient search) }\end{array}$ \\
\hline \multicolumn{5}{|l|}{ Measures } \\
\hline Name & $\begin{array}{l}\text { Processing stage } \\
\text { targeted }\end{array}$ & Description & When to use & Considerations \\
\hline $\begin{array}{l}\text { Demand } \\
\text { selection }\end{array}$ & $\begin{array}{l}\text { Before task } \\
\text { performance }\end{array}$ & $\begin{array}{l}\text { Participants choose in advance one of } \\
\text { two possible tasks they would prefer to } \\
\text { perform }\end{array}$ & $\begin{array}{l}\text { To assess prospective strategy choices prior } \\
\text { to task performance }\end{array}$ & $\begin{array}{l}\text { Consistently choosing one task may produce } \\
\text { asymmetric practice effects }\end{array}$ \\
\hline Target choice & Stimulus selection & $\begin{array}{l}\text { Multiple targets are present in a visual } \\
\text { search, of which participants need only } \\
\text { identify just one }\end{array}$ & $\begin{array}{l}\text { To assess strategy choices during task } \\
\text { performance; when seeking strategy } \\
\text { indicators on single trials }\end{array}$ & $\begin{array}{l}\text { To prevent participant tendencies to always choose the } \\
\text { same target, task contingencies or environmental } \\
\text { properties can be varied over time }\end{array}$ \\
\hline $\begin{array}{l}\text { Saccadic } \\
\text { choice }\end{array}$ & Stimulus selection & $\begin{array}{l}\text { Measures which items/locations are } \\
\text { fixated }\end{array}$ & $\begin{array}{l}\text { When eye movements are a critical } \\
\text { component of task performance; when } \\
\text { seeking strategy indicators on single trials }\end{array}$ & $\begin{array}{l}\text { No manual response required; does not measure covert } \\
\text { shifts of attention (i.e., those occurring without eye } \\
\text { movements) }\end{array}$ \\
\hline $\begin{array}{l}\text { RT/Accuracy } \\
\text { difference } \\
\text { scores }\end{array}$ & Stimulus selection & $\begin{array}{l}\text { Compares response metrics across } \\
\text { multiple conditions to infer strategy }\end{array}$ & $\begin{array}{l}\text { When task measures of interest, such as } \\
\text { distraction effects, are calculated across } \\
\text { multiple conditions }\end{array}$ & $\begin{array}{l}\text { Cannot reveal strategy on single trials; difference scores } \\
\text { can have poor test/re-test reliability }\end{array}$ \\
\hline $\begin{array}{l}\text { Speed- } \\
\text { accuracy } \\
\text { tradeoff }\end{array}$ & Target decision & $\begin{array}{l}\text { Indicates the degree to which speed or } \\
\text { accuracy is prioritized }\end{array}$ & $\begin{array}{l}\text { To probe the target decision stage, which is } \\
\text { reached based on target information that is } \\
\text { accumulated over time }\end{array}$ & $\begin{array}{l}\text { Model parameters relating to boundary separation can } \\
\text { reveal dynamic changes in the tradeoff function over } \\
\text { time; cannot reveal strategy on single trials }\end{array}$ \\
\hline $\begin{array}{l}\text { Response } \\
\text { criterion }\end{array}$ & Target decision & $\begin{array}{l}\text { A metric from Signal Detection Theory } \\
\text { that reflects biases in reporting target } \\
\text { properties }\end{array}$ & To probe target decision-related processes & $\begin{array}{l}\text { Less about how attention is allocated during task } \\
\text { performance than about strategic responding under } \\
\text { uncertainty about target properties }\end{array}$ \\
\hline Patch leaving & Stay/leave decision & $\begin{array}{l}\text { Specific to foraging tasks, measuring } \\
\text { decision to abandon search and move } \\
\text { to the next display }\end{array}$ & $\begin{array}{l}\text { To understand strategic factors in foraging } \\
\text { regarding staying vs. leaving }\end{array}$ & $\begin{array}{l}\text { Can compare search strategy to well-developed models } \\
\text { of "optimal foraging" }\end{array}$ \\
\hline $\begin{array}{l}\text { Metacognitive } \\
\text { report }\end{array}$ & $\begin{array}{l}\text { Depends on } \\
\text { strategy component } \\
\text { of interest }\end{array}$ & $\begin{array}{l}\text { Collects explicit reports regarding which } \\
\text { strategy the participant believes they } \\
\text { used }\end{array}$ & $\begin{array}{l}\text { To compare beliefs about chosen strategy vs. } \\
\text { actual strategy used }\end{array}$ & $\begin{array}{l}\text { Should be combined with additional strategy metrics to } \\
\text { enable comparison between reports and strategy used }\end{array}$ \\
\hline $\begin{array}{l}\text { Subjective } \\
\text { effort ratings }\end{array}$ & $\begin{array}{l}\text { Depends on } \\
\text { strategy component } \\
\text { of interest }\end{array}$ & $\begin{array}{l}\text { Collects explicit ratings indicating how } \\
\text { demanding a task is perceived to be }\end{array}$ & $\begin{array}{l}\text { To understand the role of effort in strategy } \\
\text { choice }\end{array}$ & $\begin{array}{l}\text { Should be combined with additional strategy metrics; } \\
\text { rating scales may suffer some degree of unreliability }\end{array}$ \\
\hline
\end{tabular}

